Tersedia online di: http://ejournal-balitbang.kkp.go.id/index.php/bawal
e-mail:bawal.puslitbangkan@ gmail.com
BAWAL WIDYA RISET PERIKANAN TANGKAP
Volume 10 Nomor 1 April 2018
p-ISSN: 1907-8226
e-ISSN: 2502-6410
BAWAL
Nomor Akreditasi: 620/AU2/P2MI-LIPI/03/2015

\title{
DINAMIKA POPULASI DAN LAJU PEMANFAATAN IKAN BANDENG (Chanos chanos) DI WADUK SEMPOR, JAWA TENGAH
}

\section{POPULATION DYNAMIC AND EXPLOITATION RATE OF MILKFISH (Chanos chanos) IN THE SEMPOR RESERVOIR, CENTRAL JAVA}

\author{
Aisyah*1, Chaerulwan Umar ${ }^{1}$, Setiya Triharyuni ${ }^{1}$ dan Husnah ${ }^{1}$ \\ ${ }^{1}$ Pusat Riset Perikanan, J1. Pasir Putih II, Ancol Timur, Jakarta Utara-14430, Indonesia \\ Teregistrasi I tanggal: 04 Agustus 2017; Diterima setelah perbaikan tanggal: 08 Februari 2018; \\ Disetujui terbit tanggal: 26 Januari 2018
}

\begin{abstract}
ABSTRAK
Ikan bandeng (Chanos chanos) di Waduk Sempor diintroduksi pada tahun 2014 melalui penerapan teknologi perikanan tangkap berbasis budidaya (Culture Based Fisheries, CBF). Penelitian ini bertujuan untuk mengevaluasi pertumbuhan bandeng melalui pengamatan parameter pertumbuhan dan biologi populasinya di Waduk Sempor, Jawa Tengah. Data yang dianalisis diperoleh dari hasil pencatatan enumerator periode September 2014 sampaiDesember 2015. Kajian dinamika populasi ikan bandeng yang meliputi laju pertumbuhan, laju kematian dan tingkat pemanfaatan mengacu pada persamaan Von Bertalanffy dan turunannya. Aspek biologi meliputi hubungan panjang berat mengacu pada model logistik, serta faktor kondisi. Hasil penelitian menunjukan bahwa parameter pertumbuhan panjang-asimtotik $\mathrm{L}_{\infty}=55,97 \mathrm{~cm}$ TL dan $\mathrm{K}=0,38$ per tahun. Laju kematian total $(\mathrm{Z})=1,17$ per tahun, kematian alami $(M)=0,56$ per tahun, kematian akibat penangkapan $(F)=0,61$ per tahun serta laju eksploitasi $(\mathrm{E})=0,5$. Pertumbuhan populasi dan laju pemanfaatan menunjukkan bahwa bandeng sudah dimanfaatkan secara optimal oleh masyarakat di sekitar Waduk Sempor.
\end{abstract}

Kata Kunci: Parameter populasi; laju kematian; tingkat pemanfaatan; bandeng; Chanos chanos; Waduk Sempor

\section{ABSTRACT}

Milkfish (Chanos chanos) was introduced at 2014 in the Sempor Reservoir through culture based fisheries $(C B F)$ technology. This study aims to evaluate population growth of the milkfish in Sempor Reservoir. Data were collected from September 2015 to December 2016, and were analyzed using excel 2007 programe manually. Analysis of length-weight relationship is refers to logistic model, population dynamic like growth rate, mortality and mortality rate are refers to Von Bertalanffy. Biology of population like length-weight relationship are refers to logistic model, and condition factor. The results showed that growth parameters were $L \infty=55.97 \mathrm{~cm} T L$ and $K=0.38$ year -1 . Total mortality $(Z)=1.17$ year $-1 ; M=0.56$ year $-1 ; F=0.61$ year $-1 ;$ and $E=0.5$. This finding stated that the growth rate and exploitation rate of Milkfish in the Sempor Reservoir has been optimally exploited.

\section{Keywords: Growth; exploitation rate; Milkfish; Chanos chanos; Sempor Reservoir}

\section{PENDAHULUAN}

Ikan bandeng (Chanos chanos) tergolong spesies euryhaline karena memiliki kemampuan hidup di air tawar maupun laut dengan salinitas hingga 158 per mil (Crear, 1980; Swanson, 1998). Siklus hidupnya meliputi fase awal yaitu pemijahan yang terjadi di laut terbuka pada kedalaman 10-40 m (Garcia 1990; Gordon \& Hong 1986), fase larva berkembang di pantai 2-3 minggu kemudian, Korespondensi penulis:

e-mail:icha_saraimanette@yahoo.com

Telp. 081654919449 dan fase juvenil dengan ekosistem perairan yang lebih kompleks seperti pantai, muara sungai, mangrove, laguna, dan rawa, hingga sungai dan danau (Bagarinao, 1994).

Ikan bandeng yang terdapat di perairan tawar di Indonesia pada umumnya merupakan jenis introduksi melalui program penebaran ikan dan penerapan teknologi perikanan tangkap berbasis budidaya (Culture Based Fisheries, CBF). Teknologi CBF pada dasarnya 
diaplikasikan di suatu badan air yang relatif kecil baik yang sifatnya permanen maupun tidak, dengan tujuan menyediakan tambahan penghasilan bagi masyarakat di sekitar badan air tersebut (Lorenzen et al., 2001 dalam Ingram \& De-Silva, 2015).

Teknologi CBF telah dikembangkan di beberapa perairan waduk sejak tahun 1999 dan menunjukkan hasil yang baik (Kartamihardja, 2015) seperti di Waduk Darma (Kuningan-Jawa Barat), Waduk Ir. H. Djuanda (JatiluhurJawa Barat), Waduk Malahayu (Brebes-Jawa Tengah), Waduk Gajah Mungkur (Wonogiri-Jawa Tengah) dan yang terakhir di Waduk Sempor (Kebumen, Jawa Tengah) (Umar et al., 2016). Keberhasilan CBF selain ditentukan oleh perencanaan yang matang secara ilmiah juga ditentukan oleh evaluasi stok ikan yang telah ditebar (Cowx, 1999). Dinamika populasi dan tingkat pemanfaatan merupakan salah satu parameter penting yang dibutuhkan dalam mengelola stok ikan. Dinamika populasi akan menentukan apakah status dari stok ikan pada kondisi pemanfaatan rendah (under exploited) atau tinggi (over exploited) (Pope et al., 2010) sehingga akan menentukan strategi penebaran ulang stok ikan dalam $\mathrm{CBF}$.

Di Indonesia, CBF ikan bandeng telah dilakukan di Danau Laut Tawar, Waduk Djuanda, Waduk Sempor (Umar et al., 2016) dan Waduk Sermo (Pranoto, 2016). Sementara kajian dinamika stok ikan yang ditebar khususnya ikan bandeng masih terbatas, yaitu di Waduk Djuanda (Tjahjo \& Purnamaningtyas, 2009) dan di W. Sermo (Pranoto, 2016).

Penelitian bertujuan untuk mengevaluasi status stok bandeng melalui parameter dinamika populasi dan tingkat pemanfaatannya di Waduk Sempor, Jawa Tengah. Hasil penelitian diharapkan dapat dijadikan acuan dalam pengembangan strategi penebaran ikan bandeng di Waduk Sempor. Di samping itu, dengan adanya penelitian ini akan dapat menambah informasi ilmiah mengenai kajian ikan bandeng yang sangat jarang dijumpai terutama di bidang perikanan tangkap. Beberapa penelitian bandeng hanya merupakan kajian dari aspek budidaya terutama pembesarannya di tambak dan kolam pemeliharaan yang termonitor serta implikasi penebarannya di waduk (Lazarus \& Nandakumaran, 1986; Borlongan \& Coloso, 1992; Mansyur \& Tonnek, 2003; Malik, 2010; Triyanto, 2010).

\section{BAHANDANMETODE \\ Waktu dan Lokasi}

Penelitian dilaksanakan di Waduk Sempor, Kabupaten Kebumen, Propinsi Jawa Tengah tahun 2015 (Gambar 1.).

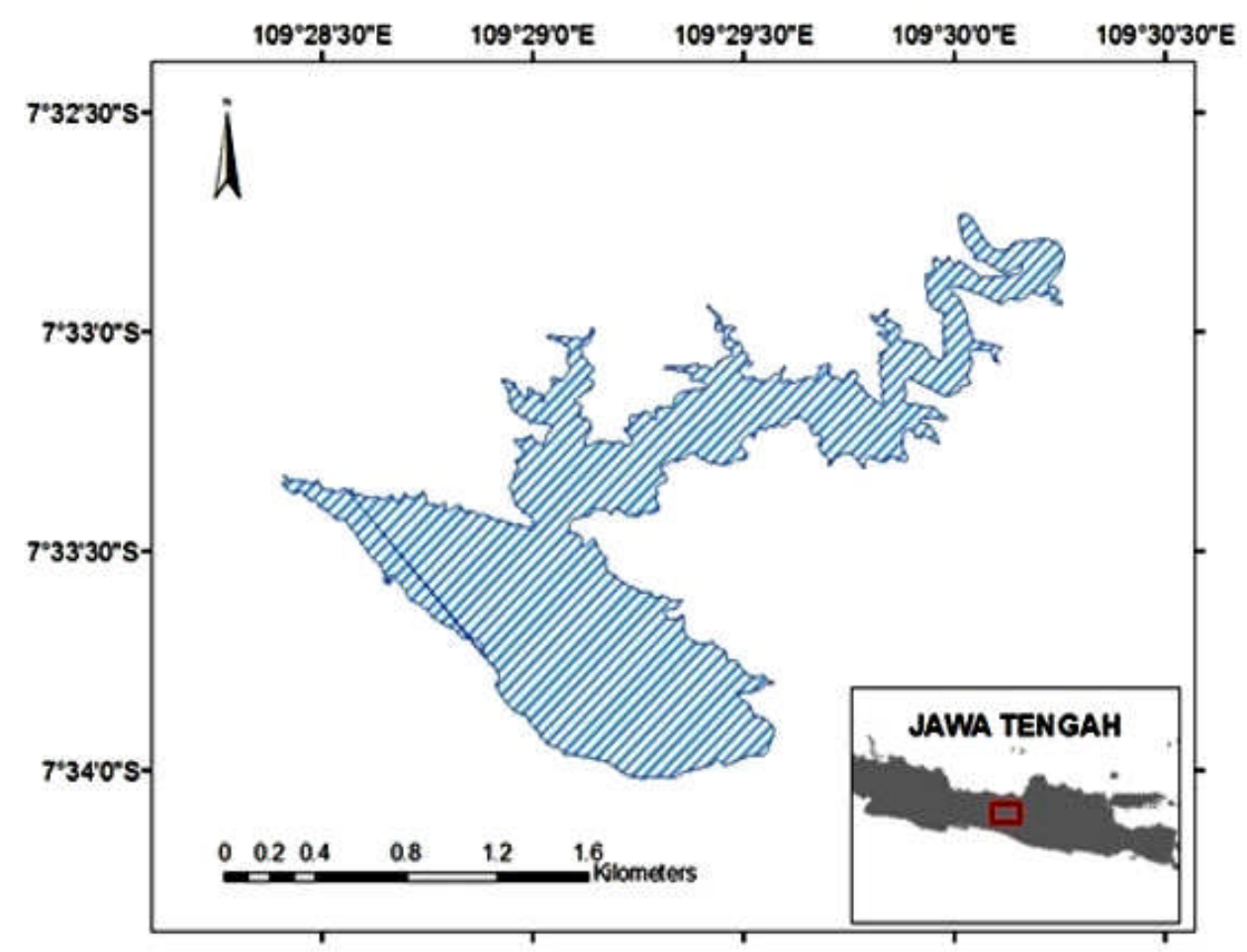

Gambar 1. Peta menunjukan lokasi penelitian di Waduk Sempor, Kebumen.

Figure 1. Map showing research location at Sempor reservoir, Kebumen. 


\section{Pengumpulan Data}

Data yang dikumpulkan berupa panjang total (totallength) dan bobot tubuh ikan (weight) yang diukur oleh enumerator. Periode pengumpulan data berlangsung selama 16 bulan, yaitu dari September 2014 sampai Desember 2015. Data ikan bandeng yang dikumpulkan merupakan hasil tangkapan gillnet dan jala yang bersifat harian.

Data curah hujan harian (mm) dan tinggi muka air (m) dari Januari 2013 sampai dengan Oktober 2015 diperoleh dari Balai Besar Wilayah Sungai (BBWS) Serayu-Opak.

\section{Analisis Data}

\section{Parameter Pertumbuhan}

Model umum yang dipakai untuk menentukan parameter pertumbuhan menggunakan model standar dalam dinamika populasi, yaitu persamaan von Bertalanffy, sedangkan analisa data digunakan persamaan yang dikemukakan Sparre dan Venema (1998) sebagai berikut:

$\left.\mathrm{L}_{\mathrm{t}}=\mathrm{L}_{\infty} 1-\mathrm{e}^{-\mathrm{k}(\mathrm{t}-\mathrm{t})} \mathrm{o}\right)$

dimana;

$\mathrm{L}_{\mathrm{t}} \quad=$ panjang bandeng pada umur $\mathrm{t}(\mathrm{mm})$

$\mathrm{L}_{\infty}=$ panjang asimptotik

$\mathrm{K}=$ koefisien pertumbuhan bandeng untuk mencapai $\mathrm{L}_{\infty}$ (tahun)

$\mathrm{t}_{0}=$ pertumbuhan pada tahun ke 0

$\mathrm{t}=$ waktu pada saat panjang ikan Lt.

Untuk mengetahui $\mathrm{t}_{\mathrm{o}}$ adalah dengan menggunakan persamaan empiris Pauly (1984) yaitu:

$\log \left(-t_{0}\right)=-0,3922-0,2752\left(\log L_{\infty}\right)-1,038(\log K)$

Untuk mendapatkan umur relatif pada berbagai ukuran panjang digunakan penurunan rumus Von Bertalanffy oleh Gulland (1983) sebagai berikut:

$-\ln \left(1-\left(\mathrm{Lt} / \mathrm{L}_{\infty}\right)=-\mathrm{kt}_{\mathrm{o}}+\mathrm{kt}\right.$

$\mathrm{t}=\mathrm{t}_{\mathrm{o}}-\ln *\left(1-\left(\mathrm{Lt} / \mathrm{L}_{\infty}\right)\right.$

\section{Pendugaan Laju Kematian}

Laju kematian (Z) merupakan laju penurunan terhadap stok. Laju kematian dapat diduga dengan menggunakan persamaan yang dikemukakan oleh Beverton \& Holt (1956) dalam Sparre et al. (1989). Z dapat diduga dari rata-rata panjang ( $)$ hasil tangkapan suatu populasi ikan bandeng, dengan persamaan sebagai berikut:
$Z=\frac{K\left[l_{\infty}-\hat{l}\right]}{[\hat{l}-l c]}$

dimana;

$\mathrm{Z} \quad=$ laju kematian total (pertahun)

$1_{\infty}=$ panjang maksimum ikan

$\hat{l}=$ panjang rata-rata ikan yang tertangkap

$\mathrm{lc}=$ ukuran dari kelas terkecil dari ikan yang tertangkap

$\mathrm{K}=$ koefisien laju pertumbuhan

Pendugaan kematian alami (M) dapat dihitung dengan menggunakan rumus Ricker \& Efarnov (1976) dalam Sparre et al. (1989) yaitu:

$\log (M)=-0,066-0,279 \log \left[L_{\infty}\right]+0,6543 \log [K]+0,4634 \log [T] . .(6)$

dimana;

$\mathrm{M} \quad=$ kematian alami

$\mathrm{L}_{\infty}$ dan $\mathrm{K}=$ parameter pertumbuhan

$\mathrm{T}=$ temperatur rata-rata atau yang disimulasikan

Nilai laju kematian total (Z) ikan bandeng diperoleh dengan memasukan parameter pertumbuhan yang telah diperoleh dari perhitungan sebelumnya. Pendugaan laju kematian alami (M) dapat diperoleh dari perhitungan persamaan Pauly dengan menggunakan parameter $\mathrm{L}_{\infty}, \mathrm{k}$ dan rata-rata suhu perairan dimana bandeng tersebut ditangkap. Nilai kematian karena penangkapan (F) dapat dihitung dengan nilai dari kematian total dikurangi nilai dari kematian alami $(\mathrm{F}=\mathrm{Z}-\mathrm{M})$.

\section{Tingkat Pemanfaatan}

Laju penangkapan atau tingkat pemanfaatan secara analitik (E) dapat dihitung dengan rumus yang dikemukakan oleh Gayanilo et al. (2005) sebagai berikut:

$E=\frac{F}{Z}$

dimana;

$E=$ tingkat pemanfaatan

$F=$ kematian karena penangkapan

$Z=$ kematian total

Jika :

$E>0,5$ over fishing

$E<0,5$ under fishing

$E=0,5$ optimal 


\section{Panjang-Berat dan Faktor Kondisi}

Hubungan panjang dan berat ikan bandeng diperoleh dari data biologi yang terdiri dari panjang total $(\mathrm{cm})$ dan berat individu ikan (g). Analisa data menggunakan formula yang dikemukakan oleh Hile (1936) dalam Effendie (1979) sebagai berikut:

$$
W=a L^{b}
$$

dengan $\mathrm{W}$ adalah berat ikan (g), a dan b adalah konstanta dan $\mathrm{L}$ adalah panjang total ikan $(\mathrm{cm})$.

Menurut Ricker dalam Effendie (1979), apabila:

1. Nilai $\mathrm{b}<3$, berarti pertambahan panjang ikan lebih cepat dibanding pertambahan berat. Pertumbuhan yang demikian disebut pertumbuhan yang demikian disebut alometrik negatif.

2. $b>3$, berarti pertambahan panjang tidak secepat pertambahan berat. Pertumbuhan yang demikian disebut pertumbuhan alometrik positif.

3. $b=3$, berarti pertambahan panjang seimbang dengan pertambahan berat. Pertumbuhan yang demikian disebut pertumbuhan isometrik.

Untuk mengetahui apakah ada perbedaan dari nilai $b$ yang didapat maka diuji dengan uji t sebagai berikut:

$$
t_{h i t}=\frac{3-b}{S D_{b} / \sqrt{n}}
$$

dimana $\mathrm{SD}_{\mathrm{b}}$ adalah standart deviasi dari nilai $\mathrm{b}, \mathrm{N}$ jumlah ikan sample. Hipotesis dalam uji ini adalah:

$$
\mathrm{H}_{0}: \mathrm{b}=3
$$$$
\mathrm{H}_{1}: \mathrm{b} \neq 3
$$

Hasil perhitungan, jika diperoleh nilai $\mathrm{t}_{\text {hit }}<\mathrm{t}_{\text {tab }}$ maka, $\mathrm{H}_{0}$ diterima dan $\mathrm{H}_{1}$ ditolak, dan sebaliknya jika $\mathrm{t}_{\text {hit }}>\mathrm{t}_{\text {tab }}$ maka, $\mathrm{H}_{0}$ ditolak dan $\mathrm{H}_{1}$ diterima.

Faktor kondisi merupakan indikasi untuk menilai kondisi ikan dilihat dari survival dan reproduksi (Effendie,
1997). Variasi nilai faktor kondisi bergantung kepada ketersediaan makanan, umur, jenis kelamin dan kematangan gonad. Pendekatan faktor kondisi menggunakan ketentuan sebagai berikut:

Untuk pertumbuhan yang bersifat alometrik berdasarkan Le Cren (1951) dalam Froese (2006):

$$
K=\frac{w}{a L^{b}}
$$

Untuk pertumbuhan yang bersifat isometrik;

$K=\frac{w 10^{5}}{L^{3}}$

dimana;

$\mathrm{K} \quad=$ faktor kondisi

$\mathrm{W}=$ bobot ikan $(\mathrm{g})$

$\mathrm{L} \quad=$ panjang total ikan $(\mathrm{cm})$

$\mathrm{a} \& \mathrm{~b}=$ konstanta

\section{Curah Hujan dan Tinggi Muka Air}

Curah hujan harian dianalisis secara sederhana menjadi rata-rata curah hujan bulanan, demikian halnya dengan tinggi muka air. Hasil analisis ditampilkan dalam bentuk grafik menggunakan Excel 2010.

\section{HASIL DAN BAHASAN Hasil}

\section{Parameter Pertumbuhan}

Ikan bandeng di Waduk Sempor berukuran panjang total (TL) pada kisaran 14,9-57,2 cm (rata-rata 43,7 cm \pm 6,92 ) dan berat $28-1665 \mathrm{~g}$ (rata-rata $681 \mathrm{~g} \pm 268$ ) yang secara umum terbagi atas paling tidak dua kelompok umur (kohort) yang berbeda (Gambar 2 dan 3, Tabel 1). Dua kelompok umur tersebut terdiri atas bandeng yang berukuran 14,5-27,7 cm dan kelompok umur $31-57 \mathrm{~cm}$. Pada bulan Oktober 2014 - Februari 2015, frekuensi panjang ikan bandeng terdiri dari 1-2 kohort. Panjang ikan bandeng mengalami pergeseran menuju ukuran yang lebih besar dari bulan ke bulan (Lampiran 1). 


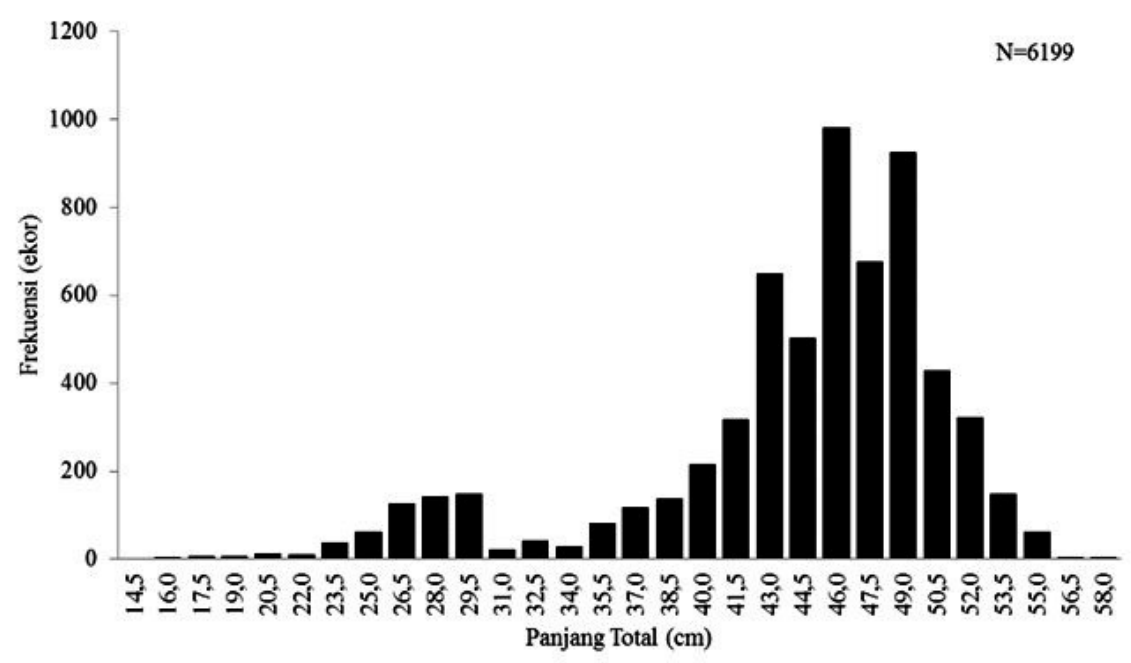

Gambar 2. Sebaran panjang ikan bandeng di Waduk Sempor, September 2014-Desember 2015.

Figure 2. Length distribution of milkfish in Sempor Reservoir, periods of September-December 2015.

Tabel 1. Parameter statistik komponen kelompok umur (kohort) 1 dan 2

Table 1. Statistical parameters of age group (cohort) 1 and 2

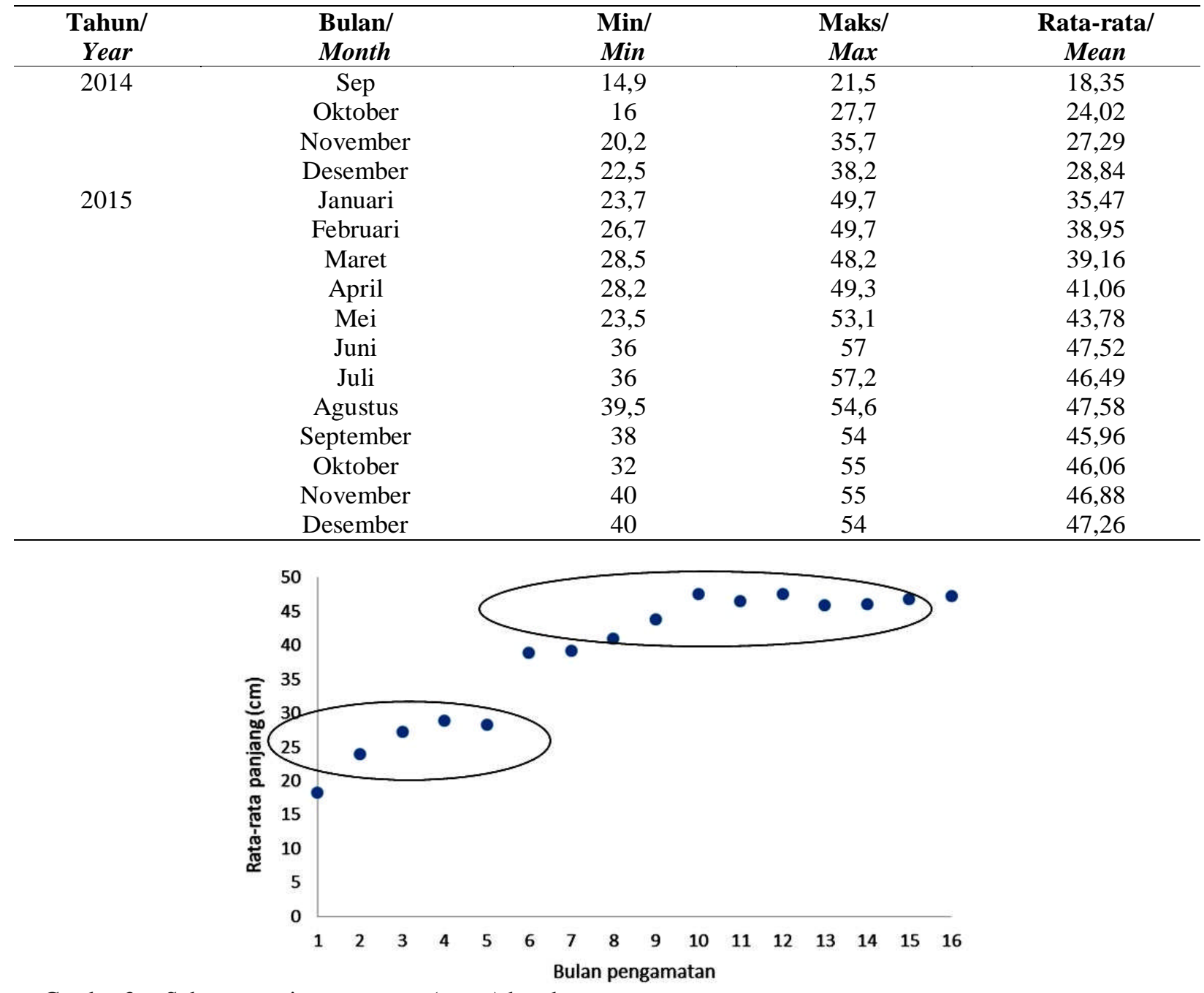

Gambar 3. Sebaran panjang rata-rata (mean) bandeng.

Figure 3. Mean length distribution of milkfish.

(Keterangan/Remarks: 1=September 2014 dst sd. 4 = Desember 2014; 5=Januari 2015 dst sd. 16=Desember 2015) 
Parameter pertumbuhan ikan bandeng yang meliputi panjang asimptotik $\left(\mathrm{L}_{\infty}\right)$ dan koefisien percepatan pertumbuhan $(\mathrm{K})$ berturut-turut adalah $\mathrm{L}_{\infty}=55,97 \mathrm{~cm} \mathrm{TL}$ dan $\mathrm{K}=0,38$ per tahun. Nilai $\mathrm{t}_{0}=0,37$ tahun. Data tersebut menunjukkan kurva pertumbuhan menurut Von Bertalanffy ikan bandeng dalam penelitian ini adalah $\mathrm{Lt}=55,97[1-\exp (-$ $0,38(\mathrm{t}-0,37)]$ (Gambar 4).

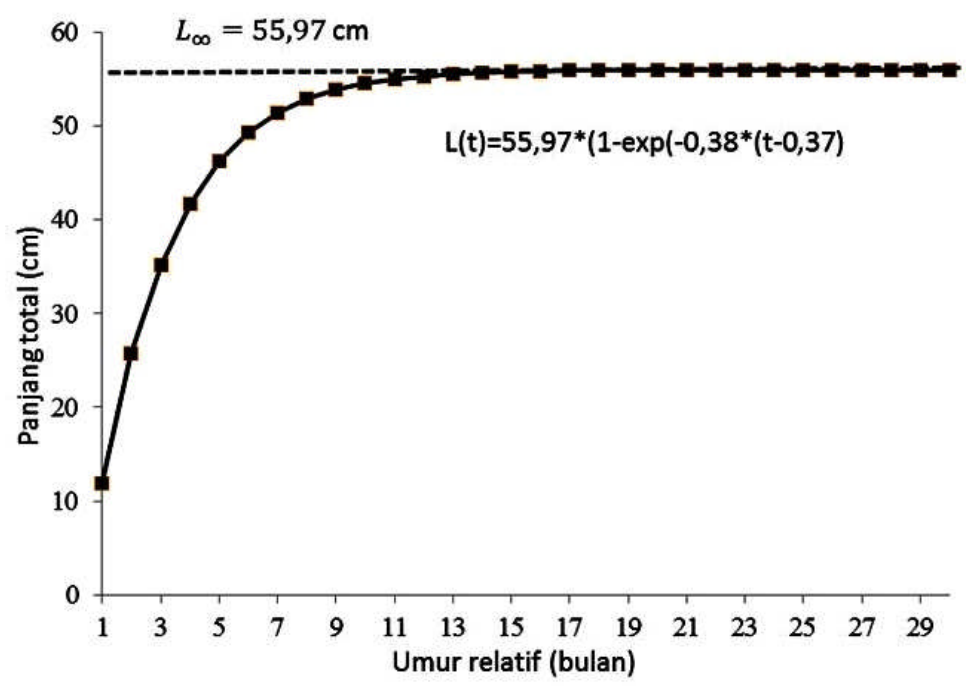

Gambar4. Kurva pertumbuhan ikan bandeng tertangkap di Waduk Sempor.

Figure 4. Growth curve of milkfish caught in Sempor Reservoir.

\section{Laju Kematian (mortality) dan Tingkat Pemanfaatan}

Laju kematian total (Z) ikan bandeng dalam penelitian ini adalah 1,17 per tahun dengan laju kematian alami (M) dan penangkapan (F) per tahun masing-masing adalah 0,56 dan 0,61. Laju kematian total merupakan fungsi dari laju pertumbuhan, panjang asimtotik dan panjang ratarata ikan. Pemanfaatan ikan bandeng di Waduk Sempor sudah pada tingkat optimal dengan nilai tingkat pemanfaatan 0,5 .

\section{Hubungan Panjang Berat dan Faktor Kondisi}

Hubungan panjang berat menunjukan bahwa pertumbuhan ikan bandeng di waduk Sempor bersifat alometrik negatif (Gambar 5). Hasil uji T menunjukan bahwa $\mathrm{T}_{\text {hitung }}(278,32)>\mathrm{T}_{\text {Tabel }}(1,65)$, hal ini menunjukkan bahwa nilai b berbeda nyata dengan nilai 3. Faktor kondisi merupakan gambaran dari kondisi bentuk tubuh ikan (Effendie, 1979). Nilainya bervariasi tergantung dari makanan, umur, jenis kelamin, dan kematangan gonad. Nilai faktor kondisi menunjukan 0,31-3,01, yang berarti ikan bandeng di Waduk Sempor dalam kondisi kurang gemuk.

\section{Tinggi Muka Air dan Curah Hujan}

Rata-rata curah hujan tahunan di Kabupaten Kebumen berkisar 0,03-28 mm (BBWS, 2015). Variasi musiman curah hujan mengikuti karakteristik iklim temporal serta perubahan iklim global di Jawa Tengah. Kondisi kritis atau kondisi air di bawah standar suplai air waduk untuk pertanian terjadi pada Agustus-September tahun 2013 dan 2014, dan Bulan Mei 2015 merupakan level terendah muka air di Waduk Sempor (Gambar 6).

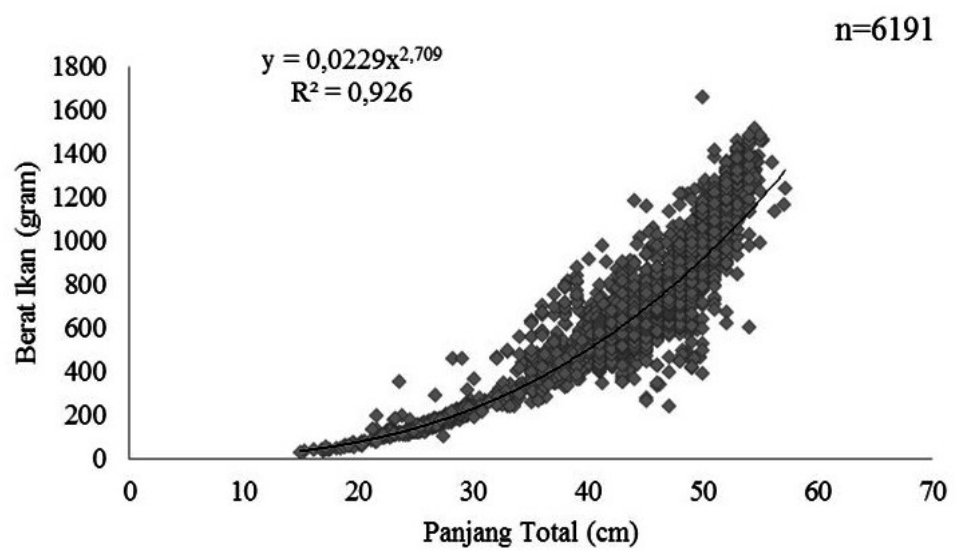

Gambar 5. Hubungan Panjang dan berat ikan bandeng di Waduk Sempor.

Figure 5. Length-weight relationship of milkfish in Sempor Reservoir. 


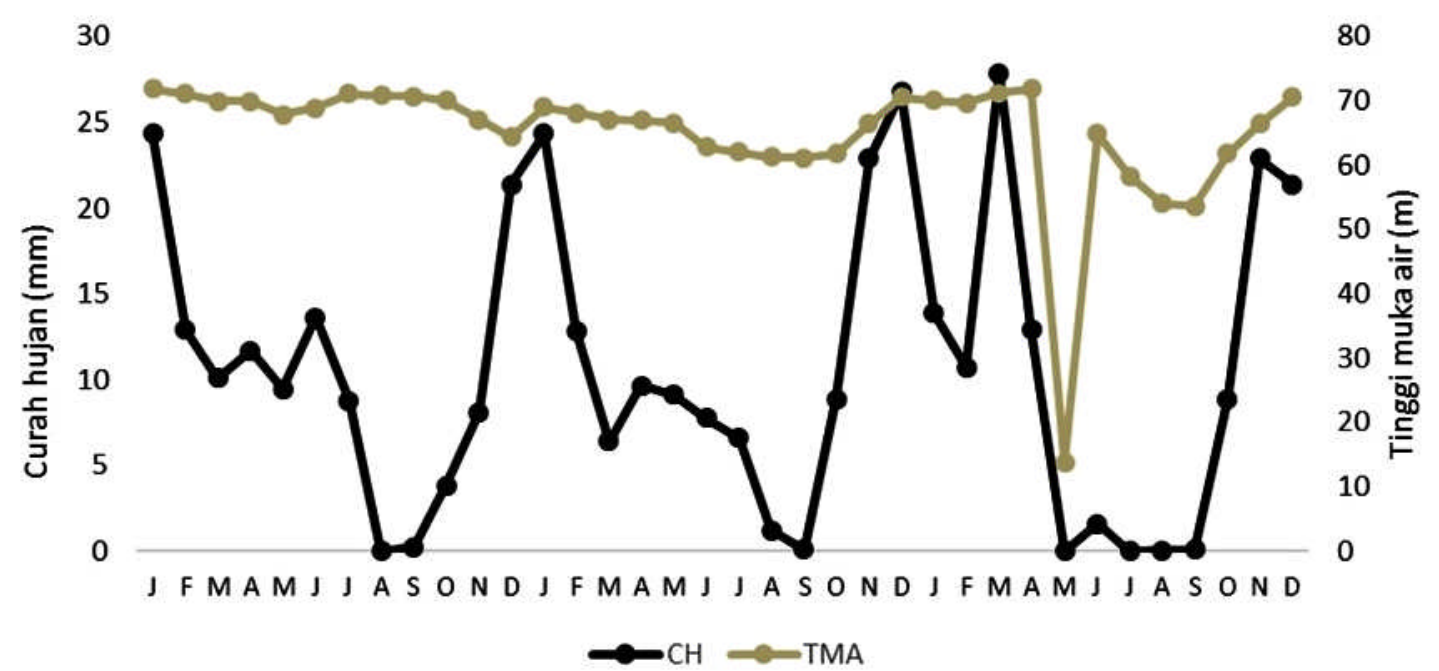

Gambar 6. Fluktuasi tinggi muka air (TMA) dan curah hujan (CH) di Waduk Sempor tahun 2013-2015.

Figure 6. Fluctuation of water level and rainfall of Sempor reservoir in 2013 - 2015.

\section{Bahasan}

\section{Pertumbuhan Populasi}

Sebaran ukuran ikan bandeng di Waduk Sempor terbagi menjadi 1-2 kohort, kohort pertama dengan intensitas rendah dan dalam jumlah sedikit berasal dari populasi bandeng pada fase awal penebaran atau tiga bulan setelah penebaran. Sedangkan kohort kedua merupakan populasi bandeng dari fase awal dan fase kedua penebaran yang mengalami pertumbuhan. Penebaran bandeng di Waduk Sempor dilaksanakan pada Bulan Juni dan September 2014 dengan ukuran benih 3-5 $\mathrm{cm}$. Ukuran bandeng di Waduk Sempor relatif lebih besar jika dibandingkan dengan bandeng di Waduk Djuanda, dimana ukuran berkisar antara 23,7-31,5 cm dan berat ratarata 134-220 g (Tjahjo et al., 2009 dalam Tjahjo \& Purnamaningtyas, 2009). Ukuran tertangkap kembali yang lebih kecil juga terjadi pada bandeng di Waduk Sermo dengan kisaran panjang dan berat 3,5-29,5 cm dan 0,29197,55 g (Pranoto, 2016).

Kemunculan 2 kohort dari populasi bandeng terlihat pada Bulan Oktober hingga Desember 2014 (Lampiran 1). Kohort pertama merupakan ukuran $14-22 \mathrm{~cm}$ (nilai modus 20,5) dan kohort kedua yang berukuran 20 - $28 \mathrm{~cm}$ (nilai modus $25 \mathrm{~cm}$ ). Kedua kelompok populasi tersebut diduga berasal dari bandeng yang pertama kali ditebar pada bulan Juni di tahun yang sama. Kemunculan kohort yang lebih kecil terjadi pada bulan Mei tahun berikutnya (2015) yang diduga merupakan populasi bandeng yang ditebar pada fase kedua yaitu bulan September 2014 yang berukuran 3$5 \mathrm{~cm}$. Dua kohort yang terlihat pada bulan Mei 2015 terbentuk dengan struktur ukuran yang sangat jelas, walaupun dari segi jumlah individu yang tertangkap sangat sedikit karena target penangkapan tidak pada ukuran tersebut. Selanjutnya panjang ikan bandeng pada kohort yang sama mengalami pergeseran menuju ukuran yang lebih besar dari bulan ke bulan. Pertumbuhan dari masingmasing kohort terlihat dari sebaran ukuran secara bulanan, dimana nilai frekuensi terbanyak mengalami pergeseran ke arah ukuran yang lebih besar.

Hubungan panjang berat ikan bandeng menunjukan sifat pertumbuhan alometrik negatif $\left(R^{2}=0,926\right)$. Sifat pertumbuhan yang berbeda ditunjukan oleh bandeng yang ditebar di Waduk Sermo pada April 2015, yaitu alometrik positif $\left(\mathrm{R}^{2}=0,994\right)$ (Pranoto, 2016). Pola pertumbuhan alometrik positif juga terjadi pada bandeng yang dipelihara di tambak di wilayah Demak (Budiasti et al., 2015). Tidak hanya di alam, pertumbuhan bandeng pada kegiatan budidaya juga mengalami fluktuasi, Malik (2010) menyatakan bahwa pemberian suplemen dan probiotik mempercepat pertumbuhan bandeng di tambak hingga 2,5 lebih cepat dibandingkan dengan tanpa perlakuan. Sudrajat (2008) menyatakan bahwa pertumbuhan harian ikan bandeng relatif cepat, yaitu 1,1-1,7 \% bobot badan atau mencapai berat rata-rata $0,60 \mathrm{~kg}$ pada usia 5-6 bulan jika dipelihara dalam tambak (Murtidjo, 2002). Lazarus \& Nandakumaran, (1986) melalui hasil percobaan pemeliharaan dengan beberapa perlakuan menyimpulkan bahwa pertumbuhan sangat terkait dengan laju makan yang harus secara kontinu dimonitor dan ditingkatkan seiring dengan bertambahnya ukuran ikan yang dipelihara.

Faktor kondisi menunjukan bahwa bandeng di Waduk Sempor tidak tergolong gemuk. Kondisi bandeng pada budidaya tambak tradisional juga tidak menjamin bandeng menjadi lebih gemuk dibandingkan pada kondisi alami seperti pada Waduk Sempor, misalnya bandeng yang dipelihara di tambak tradisional di Kabupaten Demak juga berada pada kondisi tidak gemuk $(\mathrm{K}=1,02)$ (Budiasti et al., 2015). Effendie (1979) menyatakan bahwa faktor kondisi dipengaruhi oleh kondisi habitat kaitannya dengan kondisi makanan, kelimpahan dan iklim, perbedaan waktu dan 
durasi kematangan gonad serta peningkatan atau penurunan aktifitas makan pada satu waktu tertentu atau kemungkinan perubahan populasi berdasarkan ketersediaan suplai makanan.

\section{Dinamika Populasi dan Tingkat Pemanfaatan Ikan Bandeng}

Laju pertumbuhan ikan bandeng di Waduk Sempor jauh lebih lambat jika dibandingkan dengan bandeng yang tertangkap di Waduk Djuanda. Analisa pertumbuhan Von Bertalanfy menunjukan bahwa laju pertumbuhan $(\mathrm{K})$ bandeng di W. Sempor hanya 0,38 per tahun sementara di W. Djuanda 3,381 per tahun (Tjahjo \& Purnamaningtyas, 2009) dan 2,50 di W. Sermo (Pranoto, 2016). Laju pertumbuhan bandeng di W. Djuanda yang sangat cepat ini bahkan mengalahkan pertumbuhan nila yang pada umumnya berkembang pesat di perairan waduk di Indonesia. Perbedaan laju pertumbuhan disebabkan oleh beberapa faktor biologi seperti perkembangan gonad, kebiasaan makan, fase pertumbuhan dan jenis kelamin (Froose, 2006).

Tidak demikian halnya dengan ukuran panjang asimptotik $\left(\mathrm{L}_{\infty}\right)$, ikan bandeng pada penelitian ini lebih panjang jika dibandingkan dengan hasil penelitian jenis ikan yang sama di W. Djuanda dan W. Sermo, dimana masing-masing memiliki $\mathrm{L}_{\infty} 45 \mathrm{~cm}$ dan 31,5. Laju pertumbuhan $(\mathrm{K})$ berbanding terbalik dengan panjang asimtotik. Jika dilihat dari $\mathrm{L}_{\infty}$ bandeng di W. Sempor yang lebih panjang, bandeng di waduk ini tidak mengalami tekanan atau eksploitasi yang luar biasa karena ukuran populasi bandeng yang tertangkap semakin besar pada bulan-bulan pengamatan. Diduga akan terjadi perubahan ukuran $\mathrm{L}_{\infty}$ jika dilakukan pengamatan setelah Desember 2015, karena ikan bandeng tidak memijah di air tawar (Bagarinao, 1994; Bagarinao, 1994 \& Reyes, 1978 dalam Garcia, 1990) yang berarti tidak ada rekruitmen baru yang dapat menyeimbangi laju eksploitasi. Di samping itu sebagaimana yang dinyatakan oleh Li et al. (1995) dalam Hariati et al. (2015) bahwa struktur data yang dikumpulkan mempengaruhi perbedaan nilai panjang asimtotik dan laju pertumbuhan.

Mengingat pertumbuhan yang sangat dipengaruhi oleh kondisi ketersediaan makanan, maka rendahnya laju pertumbuhan bandeng di Waduk Sempor yang tidak setinggi pertumbuhan bandeng di waduk lain diduga terkait dengan kondisi hidrologi Waduk Sempor yang sangat fluktuatif terutama pada fase-fase penting pertumbuhan atau sekitar 6 bulan setelah penebaran (Lazarus \& Nandakumaran, 1986). pada sekitar Desember 2014 terjadi fluktuasi air ekstrim di Waduk Sempor hingga terjadi limpasan (tinggi muka air melebihi ambang muka air limpasan). Fluktuasi air ekstrim menandakan bahwa ada pergantian air dari suatu waduk, dengan input yang berasal dari sungai-sungai di sekitarnya ditambah dengan curah hujan yang tinggi pada periode tersebut yang kemudian dialirkan ke luar (flushing) karena melebihi volume tampungan. Ketidakstabilan kondisi kolom air memicu terjadinya turbulensi sehingga menyebabkan fluktuasi biomassa plankton (Dantas et al., 2008), yang merupakan makanan bandeng. Selain bentuk ketidakstabilan level air berupa limpasan, kondisi ekstrim atau tinggi muka air di bawah standar hingga level terendah juga terjadi tahun 2015. Kondisi tersebut diduga sebagai dampak fenomena el nino dalam hal curah hujan yang mulai terjadi di Indonesia pada Maret 2015, dan periode terkuatnya pada Juli 2015. Dampak el nino termasuk berkurangnya curah hujan, terutama di wilayah Kalimantan bagian tengah dan selatan, selatan Sumatra, selatan Jawa, Sulawesi dan Papua (ACAPS, 2016).

Laju kematian total (Z) ikan bandeng dalam penelitian ini adalah 1,17 per tahun, dengan kematian akibat penangkapan (F) sedikit lebih tinggi dari pada kematian alami (M). Laju penangkapan bandeng telah mencapai kondisi laju eksploitasi optimal sumber daya ikan. Pada perairan yang dilakukan penebaran di dalamnya menandakan bahwa ikan yang ditebar atau diintroduksi mampu dimanfaatkan secara optimal oleh masyarakat di sekitarnya. Konsep tersebut sedikit berbeda dengan kondisi sumber daya ikan yang memang sudah ada di suatu perairan, karena dengan nilai laju eksploitasi yang melebihi nilai optimum $(\mathrm{E}=0,5)$ maka hal tersebut menandakan bahwa bandeng sudah dimanfaatkan secara optimal oleh masyarakat di sekitar Waduk Sempor (Gulland, 1971 dalam Pauly, 1984).

\section{KESIMPULAN}

Ikan bandeng atau milkfish (Chanos chanos) di Waduk Sempor merupakan jenis ikan yang diintroduksi tahun 2014 melalui teknologi perikanan tangkap berbasis budidaya atau Culture Based Fisheries (CBF). Dinamika populasi menunjukan bahwa ikan bandeng hasil tebaran di Waduk Sempor memiliki pertumbuhan asimtotik $\left(\mathrm{L}_{\infty}\right)$ yang relatif tinggi. Kondisi sebaliknya dengan laju pertumbuhan (K) yang sangat rendah. Rata-rata ukuran yang tertangkap lebih tinggi jika dibandingkan dengan di waduk lain, yang terkait dengan waktu penangkapan terhitung sejak awal penebaran. Laju eksploitasi (E) sebagai fungsi dari laju penangkapan dan laju kematian total (M) menunjukan bahwa bandeng sudah dimanfaatkan secara optimal oleh masyarakat di sekitar Waduk Sempor.

\section{PERSANTUNAN}

Tulisan merupakan hasil dari kegiatan: Pematangan Teknologi CBF Ikan Bandeng dan Pengendalian Ikan Asing Invasif di Waduk Sempor, Jawa Tengah di Pusat Riset Perikanan tahun 2015. 


\section{DAFTAR PUSTAKA}

[ACAPS] Assessment Capacities Project. (2016). El Niño/ La Niña Impact on Indonesia: Scenarios - Possible developments in Indonesia over the next 10 months (to end 2016). Report published on March 2016.

[BBWS] Balai Besar Wilayah Sungai. (2015). Data curah hujan dan fluktuasi muka air Bendungan Sempor). Balai Besar Wilayah Sungai Serayu Opak. Kumpulan data. p.6.

Bagarinao, T. (1994). Systematics, distribution, genetics and life history of milkfish, Chanos chanos. Env. Biol. Fishes. 39, 23-41.

Borlongan, I. G, \& Coloso, R. M. (1992). Lipid and patty acid composition of milkfish (Chanos chanos Forskal) Grown in freshwater and seawater. Aquaculture, 104 (1-2), 79-89.

Budiasti, R.R. \& Anggoro, S., Djuwito. (2015). Beban kerja osmotik dan sifat pertumbuhan ikan bandeng (Chanos chanos forskal) yang dibudidaya pada tambak tradisional di Desa Morosari dan Desa Tambakbulusan Kabupaten Demak. Management of Aquatic Resources Journal, 4 (1), 169-176.

Cowx, I.G. (1999). An appraisal of stocking strategies in the light of developing country constraint. Fisheries Management and Ecology. 6, 21-34.

Crear, D. (1980). Observating on the reproductive state of milkfish populations (Chanos chanos) from hypersaline ponds on Christmas Island (Pacific Ocean). Proc. World Maricult Soc. 11, 548-556.

Dantas, E.W., Moura, A.N., Bittencourt-Oliveira, M.C., Arruda-Neto, J.D.T., \& Cavalcanti, A.D.C. (2008). Temporal variation of the phytoplankton community at short sampling intervals in the Mundau Reservoir, Northeastern Brazil. Acta Bot. Bras. 22 (4), 970-982.

Effendie, M.I. (1979). Metode biologi perikanan (p. 140). Yayasan Dewi Sri, Bogor.

Froese, R. (2006). Cube law, condition factor and weightlength relationships: history, meta-analysis and recommendations. J. Appl. Ichthyol. 22, 241-253

Garcia, L.M. (1990). Fisheries biology of milkfish (Chanos chanos Forskal) in Proceedings of the Regional Workshop on Milkfish Culture Development in the South Pacifictarawa, Kiribati, 21-25 November 1988. South Pacific Aquaculture Development Project, Food and Agriculture Organization of the United Nations.
Gayanilo, F. C. J., Sparre, P., \& Pauly, D. (2005). FAOICLARM Stock Assessment Tools II (FISAT II). Revised version. User's guide. FAO Computerized Information Series (Fisheries) No. 8. Revised Version. Rome: FAO. 168 pp

Gordon, M.S, \& Hong, L.Q. (1986). Biology of Chanos chanos. dalam: Lee CS, Gordon MS, Watanabe WO. editor. Aquaculture of Milkfish (Chanos chanos): State of the Art. The Oceanic Institute Makapuu Point Waimanalo, Hawai. p.1-33.

Gulland, J.A. 1983. Fish stock assessment. Amanual of basic methods. John Wiley and Sons, New York. 223 pp

Hariati, T., Faizah. R. \& Nugroho, D. (2015). Umur, pertumbuhan dan laju pemanfaatan ikan banyar (Rastrelliger kanagurta Cuvier, 1816), di Selat Malaka (Wilayah Pengelolaan Perikanan-571). J. Lit. Perikan. Ind.21(1), 1-8.

Ingram, B. A. \& De-Silva, S. (2015). General aspect of stock enhancement in fisheries developments. Paper diunduh dalam bentuk pdf. p.11.

Kartamihardja, E. S. (2015). Potential of culture-based fisheries in Indonesian inland waters. In S. S. DeSilva (ed.), Perspectives on culture-based fisheries developments in Asia (pp. 73-81). Bangkok, Thailand: Network of Aquaculture Centres in Asia-Pacific.

Lazarus, S. \& Nandakumaran, K. (1986). Studies on the monoculture of Milkfish in artificial ponds. J. Mar. Biol. Ass. India, 28 (1 \& 2), 84-95.

Malik, A. (2010). Pengaruh pemberian suplemen dan probiotik terhadap hasil panen bandeng (Chanos chanos) di wilayah Desa Kentong Kecamatan Glagah Kabupaten Lamongan. Jurnal Unisla. p.57-65.

Mansyur, A. \& S. Tonnek. (2003). Prospek budi daya bandeng dalam karamba jaring apung laut dan muara sungai. Jurnal Litbang Pertanian, 22(3), 79-85.

Murtidjo, B. A. (2002). Bandeng (p. 113). Kanisius. Yogyakarta.

Pauly, D. (1984). Fish Population Dynamics in Tropical Waters: a Manual for Use with Programmable Calculators. ICLARM Stud Rev. 8, 325.

Pope, K.L., Young, M.K., \& Lochman, S. (2010). Method for assessing fish populations. In: Quist and W.A. Hubert (eds). Inland Fisheries Management of North America.3rd edition. American Fisheries Society. Besthesda, Maryland. p. 325- 350. 
Pranoto, B. E. (2016). Hubungan panjang berat dan parameter pertumbuhan bandeng (Chanos chanos) di Waduk Sermo Kabupaten Kulon Progo. Skripsi pada Jurusan Manajemen Sumber Daya PerikananUniversitas Gajah Mada. p.36.

Sparre, P. \& Venema, S.C. (1998). Introduction to Tropical Fish Stock Assessment: Manual Issue 306 of FAO fisheries technical paper. Volume 1 of Introduction to Tropical Fish Stock Assessment. Revised edition. 422 pp

Sparre, P., E. Ursin, \& Venema, S. C. (1989). Introduction to tropical fish stock assessment. Part 1 Manual FAO. Fisheries Tech. Rome.

Sudradjat, A. (2008). Budidaya 23 komoditas Laut Menguntungkan. Penebar Swadaya, Jakarta. 176 pp

Swanson, C. (1998). Interactive effects of salinity on metabolic rate, activity, growth and osmoregulation in the euryhaline milkfish (Chanos chanos). J. Biol. Chem. 201, 355-366.

Tjahjo, D.W.H, \& Purnamaningtyas, S.E. (2009). Evaluasi kemampuan ikan bandeng dan nila tebaran dalam memanfaatkan kelimpahan fitoplankton di Waduk Ir. H. Djuanda. Prosiding Forum Nasional Pemacuan Sumberdaya Ikan II. Loka Pemacuan Stok Ikan. PI-02. p.11.

Triyanto. (2010). Implikasi penebaran ikan bandeng (Chanos chanos) dalam pemanfaatan plankton di Waduk Ir. H. Djuanda, Jawa Barat. Tesis. Sekolah Pasca Sarjana - Institut Pertanian Bogor. p.127.

Umar, C., Aisyah, \& Kartamihardja, E.S. (2016). Strategi pengembangan perikanan tangkap berbasis budidaya di waduk: studi kasus introduksi ikan bandeng (Chanos chanos) di Waduk Sempor, Kabupaten Kebumen, Jawa Tengah. J. Kebijak. Perikan. Ind. 8(1), 21-28. 
Lampiran 1. Sebaran bulanan ikan bandeng di Waduk Sempor, September 2014-Desember 2015

Appendix 1. Monthly distribution of Milkfish (Chanos chanos) in Sempor Resevoir periods of September 2014 December 2015
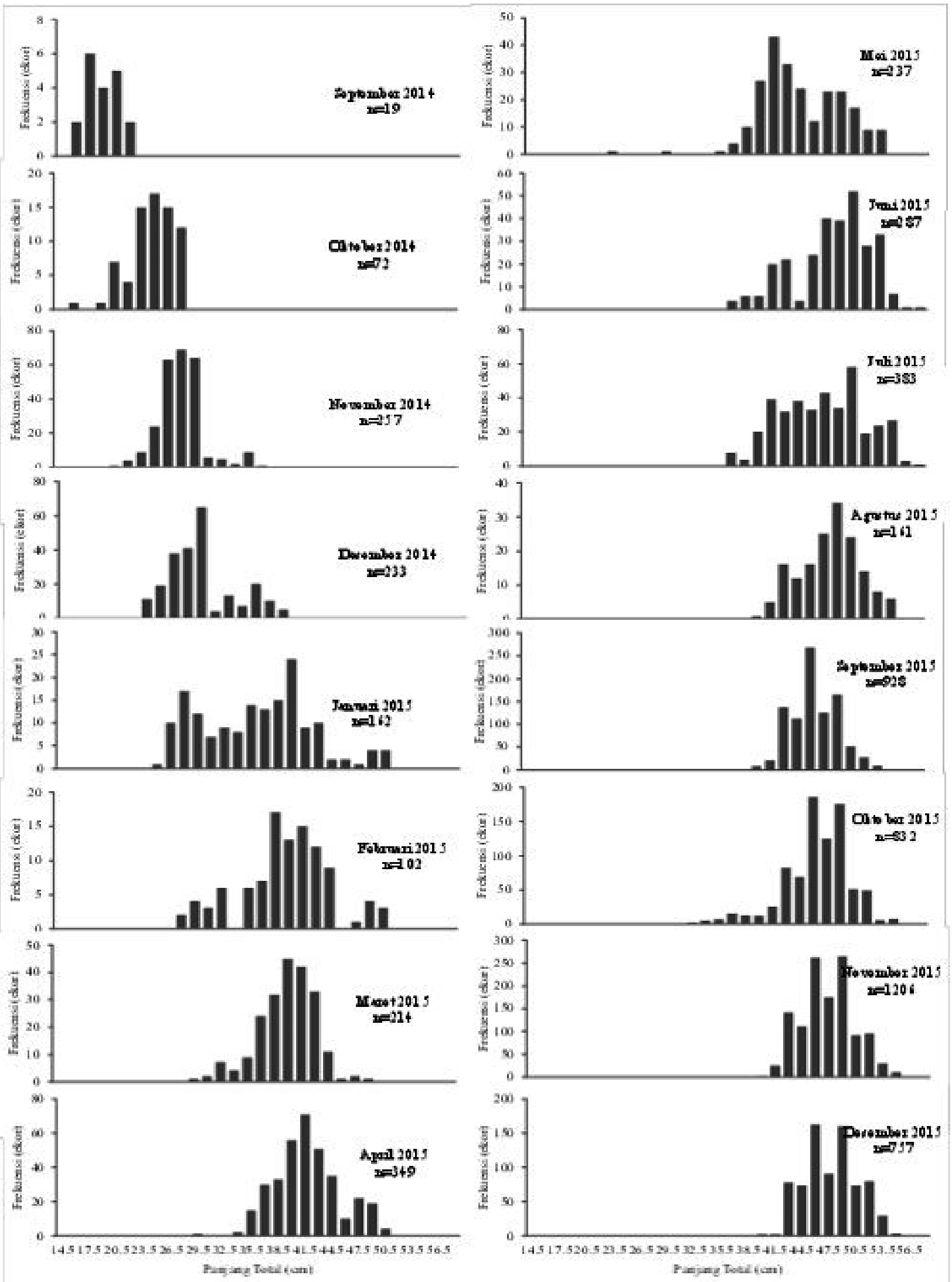